\title{
Incentives for Plastic Recycling: How to Engage Citizens in Active Collection. Empirical Evidence from Spain
}

\author{
Denisa Gibovic (D) and Andrea Bikfalvi *(D) \\ Campus de Montilivi, Department of Business Administration and Product Design, University of Girona, \\ 17071 Girona, Spain; denisa.gibovic@gmail.com \\ * Correspondence: andrea.bikfalvi@udg.edu; Tel.: +34-659-997-640
}

Citation: Gibovic, D.; Bikfalvi, A. Incentives for Plastic Recycling: How to Engage Citizens in Active Collection. Empirical Evidence from Spain. Recycling 2021, 6, 29. https:// doi.org/10.3390/recycling6020029

Academic Editors: Michele John and Wan-Ting (Grace) Chen

Received: 30 December 2020

Accepted: 22 April 2021

Published: 26 April 2021

Publisher's Note: MDPI stays neutral with regard to jurisdictional claims in published maps and institutional affiliations.

Copyright: (c) 2021 by the authors. Licensee MDPI, Basel, Switzerland. This article is an open access article distributed under the terms and conditions of the Creative Commons Attribution (CC BY) license (https:// creativecommons.org/licenses/by/ $4.0 /)$.

\begin{abstract}
The recycling target for plastics is expected to increase Europe-wide from $22.5 \%$ to $55 \%$ by 2025 , hence the relevance of incentive schemes and the need to reach conclusions about how to encourage families to recycle more. Following this objective, a pilot project was implemented and a virtual reward token called RECICLOS created to encourage recycling among families, using incentives and awards to improve recycling behaviour and a webapp prototype to register the recycled plastic. By the end of the 6-week pilot project, 1053 families were registered on the scheme, representing $10 \%$ of the targeted population in the pilot area of the county of Pla de l'Estany, Catalonia, Spain. The novelties were the introduction of a token, the gamification of incentives through raffles and lotteries, webapp-based direct communication with citizens, and feedback after collecting and registering the recycled material. The multidimensional aspects of recycling activities, their strong relation with human behavioural patterns, and the high demand for communication and interaction mean that mobile technologies find significant application in this field. The results show that people can be influenced and their recycling habits changed by means of varied, effective, and innovative incentive schemes.
\end{abstract}

Keywords: incentives; recycling; new technologies; waste management; Spain

\section{Introduction}

Over the past 50 years, there has been a consistent increase in the presence of plastics in the economy, making this an environmental challenge for society and the planet. According to the PlasticsEurope report 2020, the global production of plastics has increased twentyfold since the 1960s, reaching 360 million tonnes in 2018 [1]. In Europe, plastics production reached almost 62 million tonnes by the same year and is expected to double again over the next 20 years [1]. Nonetheless, more than 40 years after the launch of the first universal recycling symbol, the global figure for collecting plastic packaging for recycling is just $14 \%$. Each year, plastic packaging material to the value of USD $80-120$ billion is lost to the economy. Given the projected growth in production, in a business-as-usual scenario, the world's oceans could contain more plastics than fish (by weight) by 2050, as warned by the World Economic Forum's study on rethinking the future of plastic [2].

In 2018, the plastics industry provided direct employment for more than 1.6 million people in Europe, creating a turnover of more than 360 billion euros and involving close to 60,000 companies, most of them small and medium enterprises (SMEs) [3]. Although plastics production in the EU has been stable in recent years, the EU's share of the global market is falling as production increases in other parts of the world. In the EU, the potential for recycling plastic waste remains largely unexploited. The reuse and recycling of end-oflife plastics remains extremely low, particularly in comparison with other materials such as paper, glass, and metals. Around 25.8 million tons of plastic waste are generated in Europe every year [1], while less than $30 \%$ is collected for recycling. Of this amount, a significant proportion leaves the EU to be treated in third world countries, where different 
environmental standards may apply [4]. Very large quantities of plastic waste leak into the environment from different sources both on land and at sea, causing significant economic and environmental damage [1]. According to EUROSTAT [5], in 2018, the packaging waste generated was estimated at $174 \mathrm{~kg}$ per inhabitant in the EU (varying from $67.8 \mathrm{~kg}$ per inhabitant in Croatia to $227.5 \mathrm{~kg}$ per inhabitant in Germany). From 2008 to 2018, paper and cardboard were the main packaging waste materials in the EU (31.8 million tonnes in 2018), followed by plastic and glass (14.8 and 14.5 million tonnes in 2018, respectively). Finland had the highest recovery rate at $114.6 \%$, the percentage of over $100 \%$ explained by the storage and treatment of previous years' waste. Belgium has the highest recycling rate at $85.3 \%$.

Globally, 5 to 13 million tons of plastics- 1.5 to $4 \%$ of global plastics production-end up in the oceans every year [6]. It is estimated that plastic accounts for over $80 \%$ of marine litter and is transported by marine currents, sometimes over very long distances. It can be washed up on land, including uninhabited land (for example, see [7]), degrade into microplastics, or form dense areas of marine litter trapped in ocean gyres. The United Nations Environment Programme (UNEP) estimates that global damage to marine environments amounts to at least USD 8 billion per year. It is estimated that between 75,000 and 300,000 tons of microplastics are released into the environment each year in the EU [4]. While a large amount of microplastics result from the fragmentation of larger pieces of plastic waste, significant quantities also enter the environment directly, making tracking and prevention more difficult. Since plastics do not break down in the environment, this waste has been accumulating in waterways, agricultural soils, rivers, and ocean for decades [8]. Most plastics are non-biodegradable and take 450 to 1000 years to decompose when disposed of in landfills or marine environments, all the time leaking out harmful constituents into the ecosystems. The current policy framework for a circular economy at the EU level forms the basis of the future framework for actions that will change this situation.

Given their lightweight nature, flexibility, and durability, plastics are particularly effective in packaging applications, with over a third of demand for plastic material used for packaging applications [9]. The short-lived nature of plastic packaging, however, creates a huge demand for its collection and recycling. Plastics are composed of multiple chains called polymers, which are made of small molecules known as monomers connected by chemical bonds. Plastic packaging is generally made of thermoplastic resins such as polyethylene terephthalate (PET), high-density polyethylene (HDPE), polyvinyl chloride (PVC), low-density polyethylene (LDPE), polypropylene (PP), and polystyrene (PS), among others. The polystyrene (PS) category includes multilayer and other plastics that are not generally collected for recycling. The rest of the plastic types can be collected, sorted, and mechanically or chemically reprocessed into flakes and/or pellets that are used as raw materials in the manufacture of new products [10]. Different policy frameworks apply at the supra-national, national, regional, and even local (municipality) level to regulate this complex issue. The well-known pay-as-you-throw (PAYT) is a powerful instrument available to local authorities to support and optimize their waste management policy and improve the situation of urban waste generation by increasing waste separation and recycling [11]. Irrespective of the level of power/influence, all actors ultimately aim at the same goal. While some authors recognise that waste management may be very different across countries, there are commonalities in climatically and culturally homogeneous areas [12].

In December 2015, the European Commission adopted an EU Action Plan for a circular economy, identifying plastics as a key priority and committed to devising a strategy to address the challenges posed by plastics throughout the value chain, taking their entire life cycle into account. In 2017, the Commission confirmed that it would focus on plastics production and use and work towards the goal of ensuring that all plastic packaging is recyclable by 2030. The first-ever European Strategy for Plastics in a Circular Economy, adopted in January 2018, will transform the way plastic products are designed, used, 
produced, and recycled in the EU [13]. The Commission states that "The Strategy is part of Europe's transition towards a circular economy and will also contribute to reaching the Sustainable Development Goals, the global climate commitments, and the EU's industrial policy objectives". The strategy addresses three main issues: (1) How to reduce the use of fossil fuels to produce plastics; (2) How to increase plastic recycling rates; and (3) How to minimize leakage into the environment, and especially the seas. Hence, the traditional plastics industry is under pressure to improve its performance, while the bio-based and biodegradable plastics industry has the potential to increase its market share. Different countries have designed and deployed various strategies to tackle this issue, which is made more complex not only by the interaction of multiple legislative layers [14] but also because both local users and tourists intervene in the process (locals and tourists), putting pressure and responsibility on citizens as agents of change [15].

Aware that solid waste is an acute problem worldwide [16], countries in general, and Spain included, are looking for ways to change their current situation regarding recycling and to reap the possible benefits of the circular economy for the country. In 2014, only $24.32 \%$ of waste was recycled in Spain, which is several points below the European average (36\%), meaning that Spain is wasting much of its increasingly scarce and expensive resources [17]. The Spanish Strategy for the Circular Economy, "Circular Spain 2030", is the strategic framework and essential action to facilitate and promote the transition to the circular economy based on collaboration among the General State Administration, the autonomous communities, local entities, and other agents such as producers and consumers of goods. The Spanish Strategy for the Circular Economy was developed based on the corresponding Action Plans, the first of which is for the period 2018-2020. This cross-cutting Action Plan mainly but not exclusively affects the actions of the General State Administration, enabling their coordination and grouping into a framework of initiatives aimed at achieving a common purpose: the transition to the Circular Economy. In Spain, municipalities are responsible for the collection, transport, and treatment of municipal waste and they may choose to develop their own waste management and prevention programs. In 2019, each citizen deposited $17.1 \mathrm{~kg}$ of plastic containers, cans, and cartons in the yellow container and $19.4 \mathrm{~kg}$ in the blue container, with respective increases of $9.1 \%$ and $7.2 \%$ on 2018 , not because of an increase in consumption, which was $1.1 \%$, but by integrating and practicing recycling [18]. Although valuable progress has been made towards closing the gap on national and European targets in the field of plastic recycling, Spain still lags behind the best performers, calling for the need to find out more about what really motivates citizens to recycle.

In the specific case of plastics, the recycling target is expected to increase Europe-wide from the current $22.5 \%$ imposed by the Packaging Directive $94 / 62 / \mathrm{EC}$ to $55 \%$ by 2025 [13], motivated in part by rising awareness among the general public of the externalities of plastics. Reaching this target by 2025 means that more than 10 million tonnes of recycled material need to be absorbed by the end markets. Given the complexity of this challenge and the different actors involved in the recycling eco-system, there is no single solution. A multitude of measures to achieve the above-mentioned goals must be implemented by the different actors, affecting product design, waste collection, sorting, recycling, and a key actor, namely the end user.

While the circular economy is still in the process of defining its conceptual boundaries $[19,20]$, current scientific literature on recycling is far more abundant in the field of business, and particularly manufacturing, than in the area of household recycling and waste reduction, with one publication stating that " ... the monitoring of plastic waste and research into its impacts are still in their infancy" [21]. There are also myriad initiatives that go under the radar of scientific investigation and publication, and different authors qualify some fields of household recycling research as emerging. With some exceptions, authors focus their attention on a series of aspects—types and/or efficiency of collection [22]—using a monothematic approach and suggesting small-scale and/or time-limited solutions [16]. Contrarily, reality is often complex and multidisciplinary, combining legal, social, economic, 
environmental, psychological, and technological facets of recycling. Another manifesto regarding the current academic literature on recycling is outlined in [16], which states that policy makers and practitioners are not given clear advice on designing recycling programs, whose success is rooted in the motivation to recycle and possible incentives for initiating, consolidating, and spreading the recycling behaviour.

Consequently, the objective of this paper was to study the relevance of incentive schemes for household recycling to reach conclusions about how to encourage families to recycle more and better and to find out how attractive each type of incentive is among the general population and whether incentives encourage people to adopt and improve recycling practices or to follow the example of the most active people or the best recyclers. Evidence is provided based on the RECICLOS project, the aim of which was to increase public awareness and reward recycling. During the 6-week pilot deployed in different small municipalities in the county of Pla de l'Estany in Catalonia (Spain), inhabited by 32,000 people, the project was able to observe how families can be encouraged to recycle plastic at home and to find out the extent of the attraction of each type of incentive offered, namely raffles, lotteries, discounts, and donations.

The originality of the research lies in providing illustrative case evidence gained from a plastic recycling incentivising solution with a multidisciplinary perspective, which combined elements of technology (webAPP and blockchain), behaviour, social aspects (community of recyclers), and virtual tokens. The business model approach in an ecosystem framework contributes to a better understanding and clarification of stakeholders and the configuration of the essential elements to successfully deploy such initiatives. Further novel elements are linked to the solution itself, the purpose of which was to demonstrate how technology can help citizens to recycle more and better, using incentives and gamification to achieve this goal, in other words, to digitalise the recycling habit and reward system without changing the current recycling model. The system combines new digital technologies that recognize and reward those who perform the recycling task correctly, transparently, efficiently, and effectively using blockchain technology.

\section{Previous and Current Experiences}

The behavioural literature suggests that recycling is highly normed and very dependent on the role of household norms in decision making [12]. The influences on recycling behaviour seem to be low and there are few relevant academic studies of incentive schemes either for household recycling in general or focused on plastics in particular that are successful or useful on a larger scale in the longer term.

The most relevant experiences so far in terms of incentive schemes aimed at motivating citizens to recycle more and better have been implemented at the governmental level in the UK. Eunomia and Serco [12] report that rewards can be a useful tool for authorities that want to enhance the performance of their waste collection service, increase participation in recycling, increase recycling tonnages collected, or reduce residual waste. A 2006 study by AEA Technology Environment (AEAT) evaluated the household waste incentive pilot scheme implemented by the Department for the Environment, Food \& Rural Affairs (Defra) in the period 2005/06. The 14 key findings identified include the relatively low cost of offering a financial incentive compared to the comparative costs of promotion, monitoring, and evaluation. The majority $(81 \%)$ of the trials reviewed had a positive, attributable impact on raising awareness through offering an incentive. Just over half (57\%) the pilot trials had a positive, attributable impact on increasing the tonnage of recyclables collected. The report concluded that incentives can be a useful tool for authorities that want to enhance the performance of their waste collection service. Another study conducted in the UK [22] compares three main behaviour change models-doorstepping, incentives, and feedback-highlighting the pros and cons of each. Incentives have been shown to be highly effective and can be tailored to the local environment, while rewards are well received by the public and are more politically acceptable than penalties. Furthermore, incentives need to be of significant value to the householder, should only be used where there is effective 
service delivery, are expensive to deliver, and rely on effective communications, while reward schemes are often complex, making it difficult to isolate the effectiveness of the constituent parts. There is also little research on the sustainability of reward schemes once the reward is removed.

In Hong Kong, the EPD (Environmental Protection Department) introduced the GREEN\$ (Greeny Coins) smart card on 16 November 2020 to facilitate and encourage the public to use the community recycling facilities, earn GREEN\$, and exchange them for gift items. Members of the public bringing no less than $2 \mathrm{~kg}$ of recyclables to the new community recycling network can register to get a GREEN\$ smart card. Reference [23] provides empirical evidence that monetary incentives for recycling play critical roles in seeking to fulfil the waste management goal in Finland. More than half $(62.6 \%)$ of the participants agreed that the financial incentive is the main trigger of behavioural change, while $52.8 \%$ of the participants agreed that this incentive stimulates knowledge about recycling waste. Regarding local authorities wishing to implement a recycling incentive scheme, the report advises that there is no 'one size fits all' ideal solution, and each authority must first and foremost consider the barriers to recycling it needs to overcome. Moving to a different context, namely Nigeria, the same author conducted a similar study [24], asserting the hypothesis that incentives for recycling are vital for reducing and managing municipal solid waste sustainably. While most survey-based studies ask for perceptions, motivations, and behaviours, few use the surveying operation to ask for recommendations and solutions. The exception is [25], who solicit recommendations on how to positively change behaviour to reduce the improper disposal of single use plastic items in north-eastern Ohio's Lake Erie basin in the US. This study also shows that a financial incentive was the number one choice ( $42 \%$ of respondents) to encourage reusable bag use. A 2008 special issue of the journal Waste Management collected and published different worldwide initiatives illustrative of PAYT in practice, including countries like Spain [26], the Czech Republic [27], the US [28], France [29], Greece [30], Japan [31], and Ireland [32]. Although more than a decade has passed, the general aim of "finding appropriate solutions and propagating variable waste charging as a prospective approach towards sustainable waste management, while respecting the principle of subsidiary and varying local conditions and preferences" ([11], p. 2759), is still an ambition.

EU initiatives such as higher recycling targets and more effective legislation for drinking water, cutting the need for bottled water, are aimed at improving the problem since over $60 \%$ of plastic waste still comes from packaging, with only $40 \%$ of it recycled. In Spain, Ecoembes was founded in 1996 to respond to the provisions of Spanish Packaging Law $11 / 97$. Some $77 \%$ of the waste managed by Ecoembes is nowadays recycled thanks to public-private collaboration and shared responsibility.

Bearing in mind the focus of this paper, a selection of initiatives, shown in Table 1, were classified into two main groups: (i) public participation and citizen engagement initiatives representative of the key problems in waste management decision making and (ii) existing solutions to educate and motivate citizens to recycle better. The selected initiatives appear listed and are characterised by their basic features including context of application, objective, incentives used, advanced technology, connectivity with the wider eco-system, and main distinctive features. 
Table 1. A comparison of existing solutions that educate and motivate citizens to recycle.

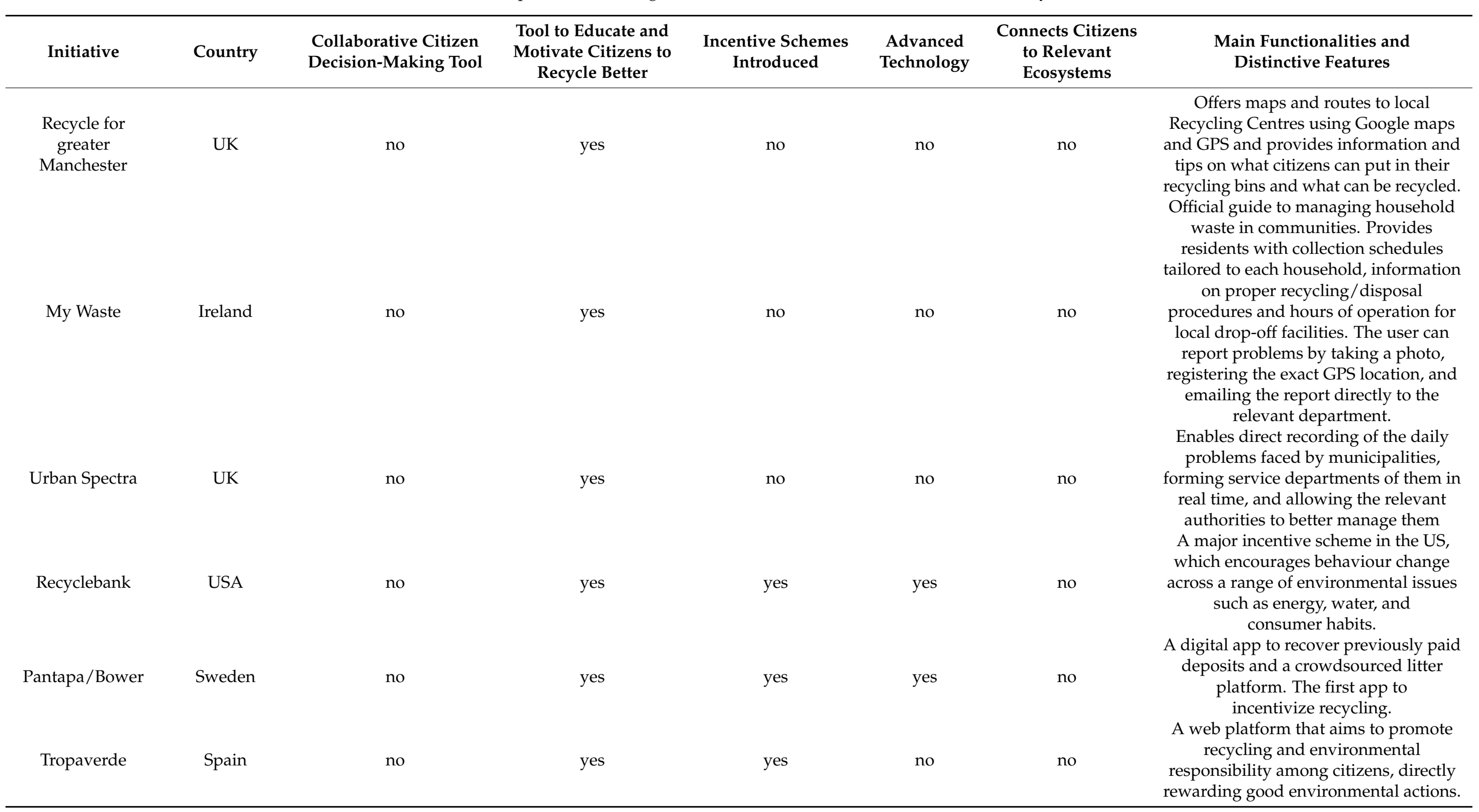


Table 1. Cont.

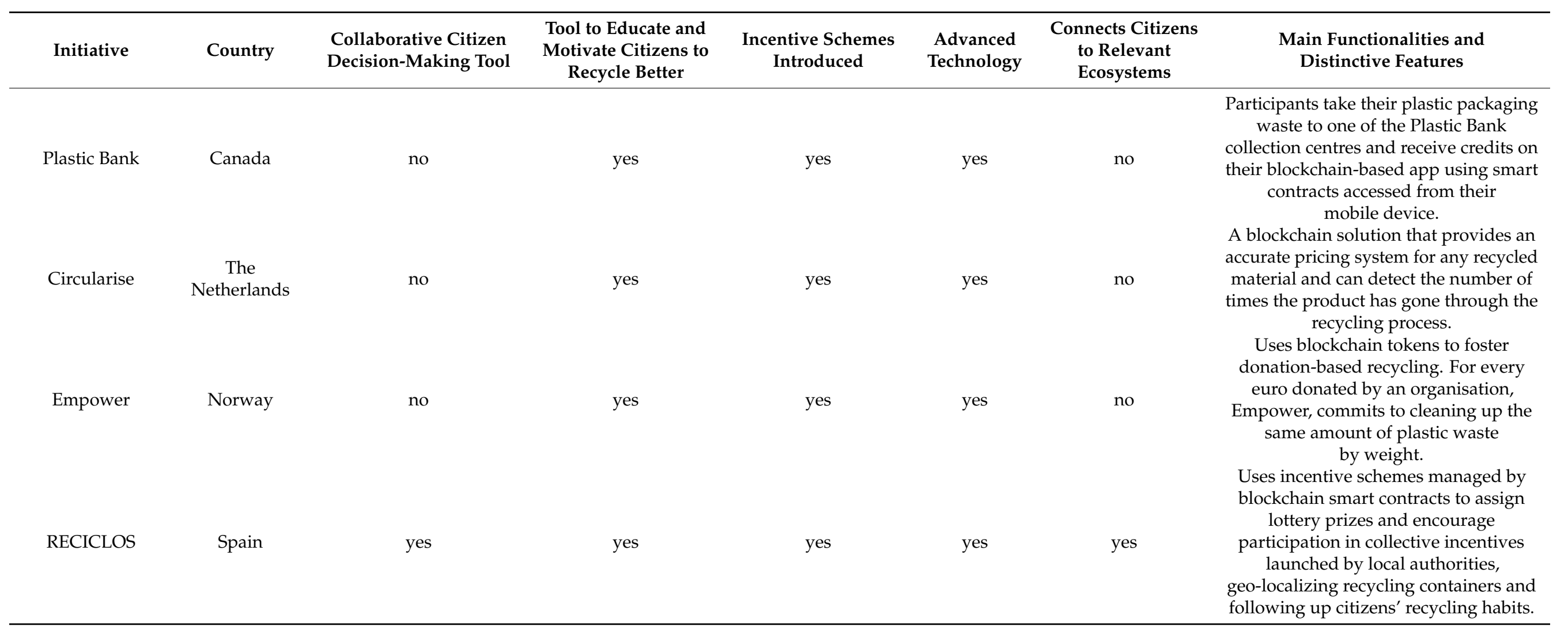


Each initiative has advantages and disadvantages, but they are all valuable for their general contribution to recycling, covering different stages or features of the recycling experience and value chain including general ambition, advice, motivation, and/or active participation in recycling, with just one initiative, Reciclos, covering all of them. The only solution comparable to RECICLOS is Recyclebank from the US, which provides incentives based on a catalogue but does not connect citizens to the relevant ecosystem or contain the advanced technology of RECICLOS. Circularise and Empower are technologically advanced solutions, but as start-ups, they lack policy support and do not connect citizens to relevant ecosystems. "Strong partnerships between interconnected plastics value chains and all stakeholders, be they local, national or global, are needed to solve this problem and to develop innovative, sustainable solutions" [1] is one of the forceful calls to connect different actors, including citizens as end users, solution providers, facilitator authorities, policymakers, Non-Governmental Organisations (NGOs), and activists for the environment.

The identification of stakeholders is an initial key step in any project. It is especially useful if they are grouped according to typologies to know how they can contribute to or oppose the project and its implementation [33]. Further, it is essential to understand different stakeholders' priorities to tailor behaviour-oriented strategies [34]. In this study, the authors find clear evidence of differences in the priorities of a broad range of stakeholders in the context of construction waste recycling, with a series of implications and a call to formulate stakeholder-specific managerial strategies and public policy tools to encourage specific stakeholders representing a certain sector to change their waste recycling behaviour.

One aspect of constraints is tied to the concept of structure paradoxes. [13] defines the Paradox of Structure as being concurrently enabling and inhibiting. The tension involving the interaction between the adaptive (efficiency of the current system and the constraints found within) and the innovative (ability to develop a more effective model) is a significant component of the Adaption-Innovation theory [14]. Some of the relevant reasons to establish "development" in a particular location [15] are cooperation with local partners and local citizen image, both pertinent in the case of local waste management innovation. All proposed innovative solutions should be viewed within the context of inner-stakeholder relations [16].

Recycling is a typical platform upon which patterns of human behaviour can be projected, since in comparison to other forms of waste management, recycling requires the most of human intervention. Since waste does not simply appear in a bag or a bin, "recyclers" must set in motion a series of "unconscious" thoughts and actions to perform the act. More specifically, recycling performance relies heavily on the actions and interactions of several stakeholders [35], each of whom-the government, consumers and waste generators, privatised waste management companies, industry and trade (and market) - has determinate roles and responsibilities, as described in [36].

Last, recycling is a practice that requires and demands the actions of a broad audience, ranging from citizens of all ages to scientists. Mobile technologies can find significant application in this field because of the multidimensional aspects of recycling activities, the strong relationship with human behavioural patterns, and the high demand for communication and interactions. According to [37], the optimum configuration for the waste management system (WMS) should consider the benefits for all stakeholders. However, with the help of current mobile technology, municipalities and citizens can together explore new opportunities for waste reduction and recycling through user driven innovation. Moreover, as stated in [35], mobile phones can act as devices that connect different stakeholders. A municipal authority can spread information about its latest campaign and introduce mobile applications to assist workers in the recycling sector, among others, while residents can find information on how to recycle different streams, organise their recycling efforts in cooperation with the municipality, and send texts, pictures, and complaints. 


\section{Methods}

\subsection{Description of the Project}

RECICLOS is a virtual reward token created to encourage recycling among families, with incentives and awards used as a mechanism to improve their recycling behaviour. It is a paradigm shift in terms of personal rewards for recycling with recyclers regularly participating in weekly and monthly raffles, jackpots, and special lotteries among other state-of-the-art incentives such as discounts on local waste taxes and donations to NGOs of the user's choice. It combines new digital technologies to create a platform that enables the monitoring and control of the flow of recycled domestic materials from homes to treatment plants, recognising and rewarding the families that do this task correctly, transparently, efficiently, automatically, and effectively using blockchain technology as today's most appropriate and reliable technology to manage the assignation of lotteries and prizes without human interaction.

\subsection{Structure of the Research/Action}

RECICLOS was first introduced with lotteries using blockchain and rewards for recycling under the motto "the luck of recycling". Lotteries are a powerful game widely used for rewarding in many B2C markets and, with the advent of virtual currencies, they are great candidates for the gamification of rewards. Indeed, lotteries are powerful gamification schemes per se and an opportunity to create a new market of recycling incentives [38]. There is a need for total trust in the rewarding programme, and its transparency is key, provided along with traceability and auditability in a distributed, compliant, and scalable way to the multiple local public administrations and companies involved in waste management using Distributed Ledger Technologies-DLTs).

The experiment undertaken in Phase 1 of RECICLOS was to develop a catalogue of 5 options that users could freely choose from and that made up a baseline of $20 \%$ uniform random to compare the preferences of several types of users. The options were the primordial tax discount bonus, donation to an NGO, the weekly or monthly raffle, the special lotteries, or donating the RECICLOS to other users, who could be offspring, parents, or friends.

The starting point is that when asked, users say they want more recycling facilities and rewards such as discounts on waste taxes. However, these discounts seem to be a rather unpopular reward among local administrations responsible for waste management as they are very much against making significant income cuts when costly recycling programs must be paid for, claiming that the top tax discount they can afford is $20 \%$. However, a regular discount of $20 \%$ or less is insignificant for most users given that in Spain this represents a yearly saving of less than 40 euros, or less than 4 euros a month, a minuscule saving compared to their individual recycling burden.

\subsection{Methods Followed for the Analysis of the Outcomes}

The design of RECICLOS is based on a few assumptions, which are detailed below.

A. Rewards like discounts and gifts are not working

For most households, the burden of recycling is way higher than whatever discounts on taxes or gifts are offered by any current incentive program. Examples of such incentives are Recyclebank in Australia, terracycle.com and wasteconnectionswichita.com in the US, "e-colones" in Costa Rica, wasted.com machines in Germany, and similar versions in Spain, including Ganamos Reciclando with their "segundos" currency. They all work from the hypothesis that Recycling is for Profit [39]. However, the amounts they produce are only attractive to minorities, while the aim of the current Proof of Concept (PoC) is to prove that the reward scheme might attract large majorities.

B. Lotteries to redistribute individual rewards might work

There are examples of redistributive raffles such as the traffic speed regulation initiative in a Swedish city, with the average speed currently standing at $30 \mathrm{~km} / \mathrm{h}$ down 
from nearly $40 \mathrm{~km} / \mathrm{h}$. The experiment proved highly effective with people keeping to the $30 \mathrm{~km} / \mathrm{h}$ speed limit following changes in the fines scheme for speed violations. All the fines were collected in a jackpot, which was shared out weekly among all the good drivers and managed randomly using smart contracts. Information about the jackpot was announced on a highly visible public display in the pertinent street.

Following this approach, it was decided to redistribute not fines but the tiny individual rewards collected via a jackpot raffled among all the good recyclers who could prove their efforts by the RECICLOS they had obtained for recycling well. Thus, instead of giving away an average of 3 euros per month per household to all 200 households in a neighbourhood, an attractive 500-euro first prize was at play, along with a second prize of 100 euros or a $10 \%$ RECICLOS reimbursement for engaging users in the next raffles as part of the gamification strategy of the recycling rewards system. Some similar examples are Vermont Recycle and Win in the US and the Australian Cash for Trash lottery.

\section{Users need transparency in lotteries and rewards programs}

There is a need for total trust in the program to keep up the reward impetus and so transparency is key. Distributed Ledger Technologies (DLTs) are therefore needed to provide solutions to achieve the required transparency, traceability, and auditability in a distributed, compliant, and scalable way among the many local public administrations and companies involved in waste management. Bringing DLT to bear on the digital asset space holds the promise of entirely new platforms for value storage, exchange, and preservation which traditional recycling and rewarding systems have so far not identified.

\subsection{RECICLOS: Implementation}

The pilot project required an objective population with a minimum of 20,000 inhabitants, the participation of up to 1000 families (the final count was 1053 families), and a control group of up to 300 families. The territory selected to implement the pilot project is in the county of Pla de l'Estany (Catalonia, Spain), an area with a total population of around 31,000 inhabitants, the nucleus of which is Banyoles with approximately 18,000 inhabitants. There are a dozen other highly dispersed municipalities and a ruralized population of between 200 and 4000 inhabitants. The focus was a population core in the municipality of Fontcoberta made up of approximately 400 predominantly young, upper-middle-class families. The pilot focused on 154 families in the Melianta neighbourhood, who became the most monitored in terms of both their participation and the quantity and quality of the waste generated. The implementation is described in the following sections.

\subsubsection{Web App}

A web app (see Figure 1), also known as a mobile web, was chosen because it helps attract new users. The two images show how users are encouraged to take part in the lotteries: (a) is an example of how a winner is announced, while (b) shows the statistical data of all the winners. An Android/IOS app will be developed in the future to secure loyalty among RECICLOS users. The look and feel of the web app are modern and focused on getting involved in Reciclos, trying your luck, and sharing your luck. 


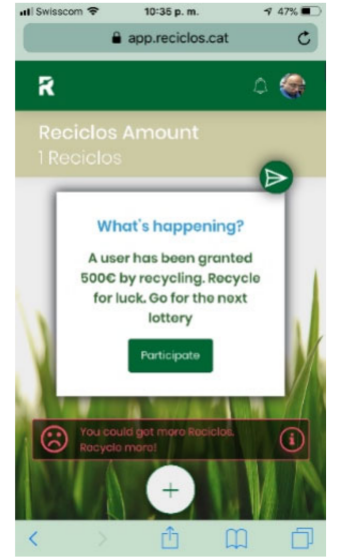

(a)

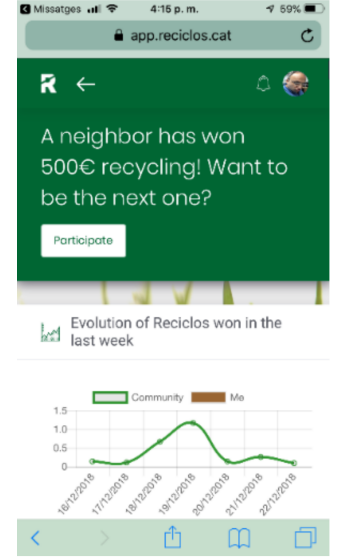

(b)

Figure 1. RECICLOS - the user interface; (a) homepage; (b) example of newsfeed to call to action.

\subsubsection{Testnet}

We worked on the Alastria testnet, a fork of Ethereum with Proof of Authority with 7 nodes as of 22 December 2018, to ensure the transparency of the system when running the lotteries and selecting the winner. Alastria is a non-profit association that promotes the digital economy through developing decentralised ledger technologies/Blockchain.

The mechanics of the system and the pilot are depicted in the diagram showed in Figure 2.
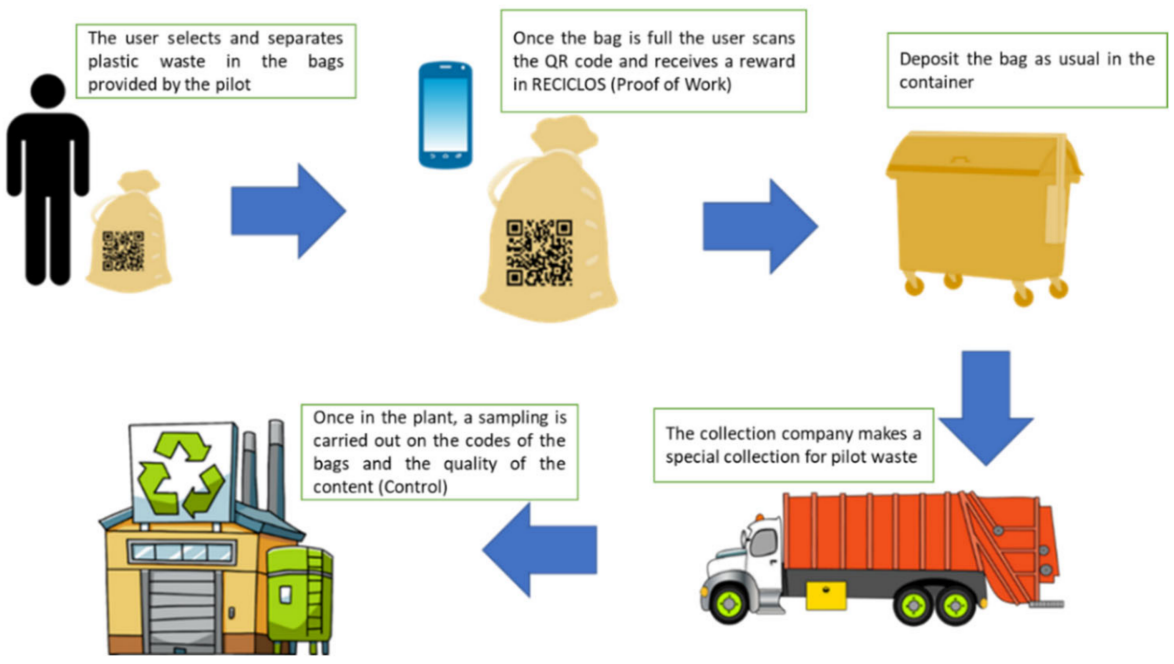

Figure 2. Mechanics and cycle of use in RECICLOS.

Those participating in the pilot project were provided with recycling bags and a unique printed QR code in the form of a label to stick on the bag. The QR code and waste bags were sent by the project team to each registered user immediately upon registration and when refills were requested. The codes for each bag were generated with an encryption so that they could not be supplanted or falsified. The Proof of Work form for users required the QR code to be scanned through the APP, receiving as a reward a RECICLOS virtual currency unit. The RECICLOS were generated and managed directly by the organization. The company URBASER made an exclusive weekly collection and on-site delivery of the bags in the focus group area of Fontcoberta. Once in the plant, the sample of bags received were analysed, the QR codes registered, and the quality of the waste checked. For the collection truck, the QR code mechanism with a locator, a 3-digit decimal number, was used to facilitate identification should the QR be illegible. 


\section{Results}

\subsection{RECICLOS: Pilot Results}

As of 20 February 2019, 6 weeks into the pilot project, 1053 families were taking part, representing $10 \%$ of the targeted population in the pilot area. Detailed figures about the families and individuals taking part in the pilot are shown in Table 2. Some $85 \%$ of the participants from 897 families were from the capital Banyoles, a result explained by the fact that $60 \%$ of the total population of the county lives there and where efforts to attract users were focused after a saturation value was reached in the Melianta neighbourhood of Fontcoberta. Fontcoberta was the municipality with the second largest number of participants in the region, at $14.6 \%$. Much of the effort was focused on the housing estate of Melianta in the municipality of Fontcoberta since its demographic characteristics were suited to the pilot project. After a 5-week door-to-door campaign, 157 families from a total of 250 on this estate were recruited to take part, making $62 \%$ of the total of the focus group from this neighbourhood and 35\% from the municipality of Fontcoberta.

Table 2. Number of participating families per municipality in the pilot county.

\begin{tabular}{|c|c|c|c|c|c|}
\hline Municipality & Total Population & $\begin{array}{l}\text { Families Participating } \\
\text { in the Pilot }\end{array}$ & $\%$ & $\begin{array}{l}\text { Persons Participating } \\
\text { in the Pilot }\end{array}$ & $\%$ \\
\hline Banyoles & 17,451 & 897 & 5.1 & 2386 & 13.7 \\
\hline Fontcuberta & 1212 & 157 & 13.0 & 418 & 34.5 \\
\hline Cornellà del Terri & 2106 & 29 & 1.4 & 11 & 0.5 \\
\hline Porqueres ${ }^{1}$ & 4208 & 20 & 0.5 & 53 & 1.3 \\
\hline Serinyà & 1084 & 19 & 1.8 & 51 & 4.7 \\
\hline Vilademuls & 76 & 8 & 10.5 & 21 & 27.6 \\
\hline Esponellà & 441 & 7 & 1.6 & 19 & 4.3 \\
\hline Palol de Revardit & 459 & 2 & 0.4 & 4 & 0.9 \\
\hline Sant Miquel de Campmajor & 218 & 1 & 0.5 & 2 & 0.9 \\
\hline
\end{tabular}

${ }^{1}$ The municipality of Porqueres was ruled out since door-to-door waste collection is carried out in this municipality.

\subsubsection{Demographic Data, Operative Systems, and WebApp Performance}

As showed in Figure 3, the users were predominantly aged between 35 and 44 years $(37 \%)$, with women taking the initiative almost double the number of times as men $(65 \%$ female users). Users aged between 25 and 34 and between 45 and 54 had very similar participation percentages of around 20\%, with those aged between 55 and 64 and the $65+$ group each accounting for around $15 \%$ of the total registered users. Regarding the operative systems, $44 \%$ of participants were using an iPhone and the rest Android phones.

The webapp performed satisfactorily in terms of capturing users, although page opening was slightly slow at $5 \mathrm{~s}$ or more. This must obviously be reduced using page optimization and by improving Alastria and cloud servers on Amazon AWS. The system was up for $99 \%$ of the time, achieved using manual supervision, a figure which must also be improved. Around $10 \%$ of users were not able to scan their waste, a figure that clearly must be reduced to $0.5 \%$. 

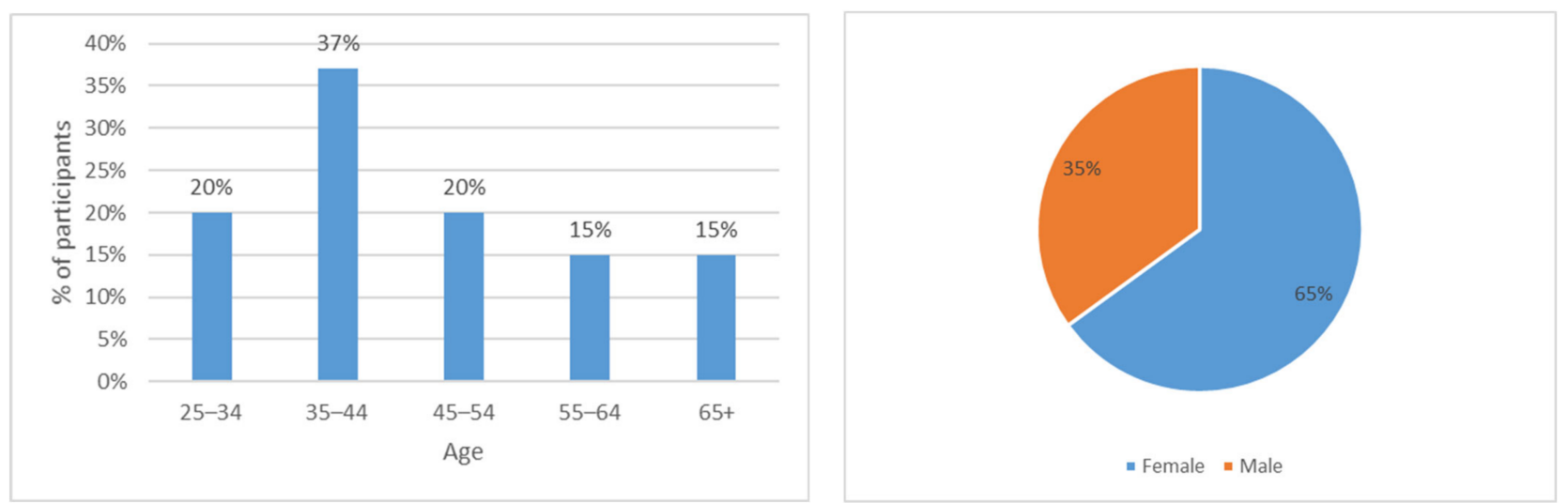

Figure 3. Basic demographic features of participants (distribution by age and gender).

\subsubsection{Creation of the User Community}

The uptake of families began in week 1 , starting on 10 December 2018, and accelerating from January 7 onwards (week 5) after consolidation of the urban centre of Melianta, the object of the focus group, and following the learning curve of the registered users and the contribution of various MGM (member-get-member) recruitments. Active uptake was deactivated in week 8 since the target of 1000 families had been reached. On 20 February 2019, there were 764 active families, 123 inactive families (without scanning), and 167 families in the initiation phase (in the last 3 weeks of the pilot project). The evolution of the rate of uptake by families is showed in Figure 4 .

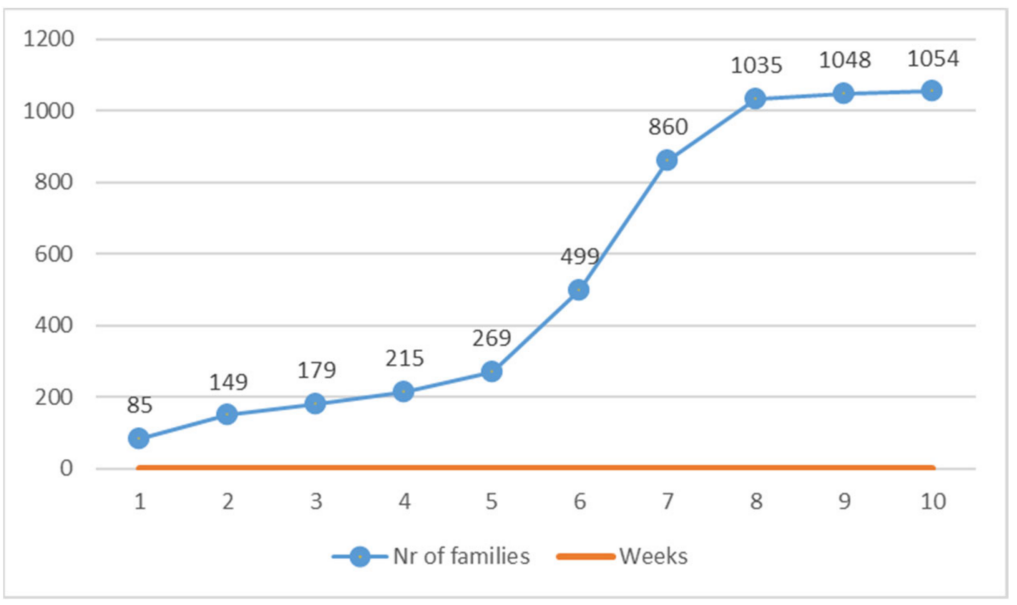

Figure 4. Rate of uptake of families.

Regarding technical difficulties, an estimated $10 \%$ of the mobile phones had problems scanning the bags with the recycled containers, explaining why 100-110 families were inactive. The ratio for the active families was 1.56 bags with recycled containers a week, while the overall ratio for the pilot project was 1.12 bags. In terms of the global figures for the 10 weeks, the 1053 families collected and registered 6749 waste bags using the RECICLOS webapp, gaining a total of 13,060 RECICLOS tokens (etherum), of which 55.5\% were used as payment to participate in the raffles and lotteries. The prizes won, however, were real objects handed out to the winners.

The nine containers in Fontcoberta were collected once a week by the region's concessionary company, URBASER, who delivered the waste to the TIRGI treatment plant in Celrà de Ter. The following day, the TIRGI staff members performed a characterization on the total sample delivered, classifying the contents of each bag as own waste or improper waste using the mobile APP. The bag was identified by reading the QR code or by manu- 
ally entering an identification number, and the quality of the waste was scored using the following scale:

- With $>30 \%$ of improper waste qualified as red (poorly separated);

- With $<30 \%$ and $>10 \%$ of improper waste qualified as yellow (regular);

- With $<10 \%$ of improper waste qualified as green (very well separated).

The basic criteria used was how far the waste corresponded to the yellow container and the relative weight of the waste classified as improper. Notably, some TIRGI employees took part in the project, all of whom had some initial training in the project and were given a list of criteria. Their participation in the project was rewarded with a bonus. The results of the characterizations delivered by TIRGI are presented in Table 3.

Table 3. Number of participating families per municipality in the region.

\begin{tabular}{cccc}
\hline Date & Collected Waste Weight (kg) & Properly Recycled (kg) & Improperly Recycled (kg) \\
\hline $11 / 12 / 2018$ & 520 & $346.1(66.6 \%)$ & $173.9(33.4 \%)$ \\
$02 / 01 / 2019^{1}$ & 1000 & $795.4(79.5 \%)$ & $204.5(20.5 \%)$ \\
$09 / 01 / 2019$ & 515 & $366.8(71.2 \%)$ & $148.2(28.8 \%)$ \\
$17 / 01 / 2019$ & 500 & $374.6(74.9 \%)$ & $125.4(25.1 \%)$ \\
$23 / 01 / 2019$ & 560 & $405.2(72.4 \%)$ & $154.8(27.6 \%)$ \\
$30 / 01 / 2019$ & 620 & $523.9(84.5 \%)$ & $96.1(15.5 \%)$ \\
$06 / 02 / 2019$ & 540 & $424.5(78.6 \%)$ & $115.5(21.4 \%)$ \\
$13 / 02 / 2019$ & 500 & $429.1(85.8 \%)$ & $70.9(14.2 \%)$ \\
$20 / 02 / 2019$ & 580 & $404.5(69.7 \%)$ & $175.5(30.3 \%)$ \\
\hline
\end{tabular}

${ }^{1}$ 2-week accumulation over Christmas and New Year.

Notably, the weighted average of improperly recycled waste was $22.7 \%$, while the starting point considered by TIRGI to be normal for Pla de l'Estany was the first measure of $33.4 \%$. The improvement sustained over time was 10.8 points. Moreover, worthy of comment is the fact that on 20 February the quality of the waste worsened radically to $30.3 \%$, in part because families had been informed that as of 13 February TIRGI would stop performing validations.

\subsubsection{Use of Incentives}

A total of $55.5 \%$ of the generated RECICLOS were used in the proposed incentives, which is not only a good indicator of the level of activity, but it also shows that users were mindful of their RECICLOS, directly impacting on the incentive for recycling. In Fontcoberta and in the rest of the region, it was observed that each bag contained an average of $0.66 \mathrm{~kg}$ of containers, meaning that each active family (the 764 mentioned) deposited $1 \mathrm{~kg}$ of packaging and received 1.615 RECICLOS per week. The figures show that there was regularly in excess of $700 \mathrm{~kg}$ of containers throughout the pilot project. Regarding the reward, 1 RECICLOS was awarded for each bag with recycled packaging upon being QR scanned, and then, another 1 or 2 RECICLOS were awarded depending on the validation. The funding was handled by ECOEMBES, the biggest public private partnership in charge of recycling promotion in Spain.

To test the direction and strength of the relation between the different incentives a Pearson correlation was performed (see Table 4). The correlation coefficients show a weak-to-positive relation between raffles, lottery, and discount and no relation between these options and donation. Participants that preferred lotteries and those that preferred discounts or donations form almost independent sets, further leading to the conclusion that those that preferred lotteries did not want a discount or have a donation made on their behalf and vice versa. These results can further be illustrative for the affirmation that different groups of users/participants prefer different (almost exclusive) options as a reward. 
Table 4. Relationships between type of users by incentives (Pearson correlation).

\begin{tabular}{ccccc}
\hline & Raffle & Lottery & Discount & Donation \\
\hline Raffle & 1 & $0.280^{* *}$ & $0.086^{* *}$ & 0.001 \\
Sig. (2-tailed) & & 0.000 & 0.004 & 0.965 \\
Lottery & $0.280^{* *}$ & 1 & $0.096^{* *}$ & 0.014 \\
Sig. (2-tailed) & 0.000 & & 0.001 & 0.628 \\
Discount & $0.086^{* *}$ & $0.096^{* *}$ & 1 & -0.001 \\
Sig. (2-tailed) & 0.004 & 0.001 & & 0.969 \\
Donation & 0.001 & 0.014 & -0.001 & 1 \\
Sig. (2-tailed) & 0.965 & 0.628 & 0.969 & \\
N & 1128 & & & \\
** Correlation is significant at the 0.01 level (2-tailed).
\end{tabular}

\subsection{RECICLOS: Final Results}

We increased the number of population points that actively recycled to 20 (from $60 \%$ to $80 \%$ of the population), with those who already recycled improving their waste selection by 10 points along with the corresponding reduction of improper waste (from $30 \%$ to $20 \%$ for improper waste and from $70 \%$ to $80 \%$ for well recycled packaging). If this combined increase is projected from the figure of $60 \% * 70 \%=42 \% 80 \%$ initial $* 80 \%=64 \%$ final, there were 21 points of projected improvement. Therefore, if the pilot result were extrapolated, an improvement of more than 20 points in the percentage of recycling would be expected, thus achieving $60 \%$ to converge with the European objective.

A total of 12,342 RECICLOS were generated from the registration of 6197 bags of packaging waste and subsequent validations during the period of the pilot project. The rewards chosen by the users were pre-eminently participation in weekly raffles (jackpots), with $59.5 \%$ of RECICLOS spent on this reward, followed by the discount on taxes with $29.4 \%$, participation in special lotteries with $8.2 \%$, and last, donations with $2.9 \%$.

\subsection{RECICLOS: The Role of the Media}

The RECICLOS were promoted via different dissemination channels, all with slightly different objectives and effectiveness in terms of impact on the users. Impact refers to the capture and activation of users of the webapp by means of the different types of dissemination actions to reach them. Table 5 presents the dissemination actions performed, with the most effective ones to motivate users to register and start using the system being direct contact, for instance the door-to-door actions and events. The role of the media was also relevant, especially local, regional, and national newspapers with the participation of local government representatives, who presented the initiative as relevant and positive for the area.

Table 5. Type and role of media.

\begin{tabular}{cccc}
\hline Type of Action & Objective & Effectiveness \\
\hline Door to door & Direct contact with future users; detailed information and user register & 5 \\
Events & Direct contact with future users; detailed information and user register & 5 \\
TV & Promotion and creation of the trust bases on the local TV & 3 \\
Radio & Promotion and creation of the trust bases on the local radio & 3 \\
Webpage & Detailed and constant update and information about the project and all news related & 3 \\
Newspaper & Promotion and creation of the trust bases on the local, regional and national newspaper & 4 & 3 \\
Social networks & YouTube for the promotion of project video and Twitter for constant project updates & \\
\hline
\end{tabular}

\section{Discussion}

\subsection{Business Model Platform Approach and Implementation}

The business model is considered to be a firm's DNA, illustrating how a product or a technology is commercialized and creates value for the firm [40]. Figure 5 shows how the RECICLOS should structure a community made up of the main stakeholders that 
needs to be powered by the blockchain platform. There are basically three defined roles within the platform: (i) Peer consumers: recyclers; (ii) Peer producers: public administrations and companies; and (iii) Partners: NGOs, National Lotteries, the cryptospace, local administrations, and companies devoted to waste management.

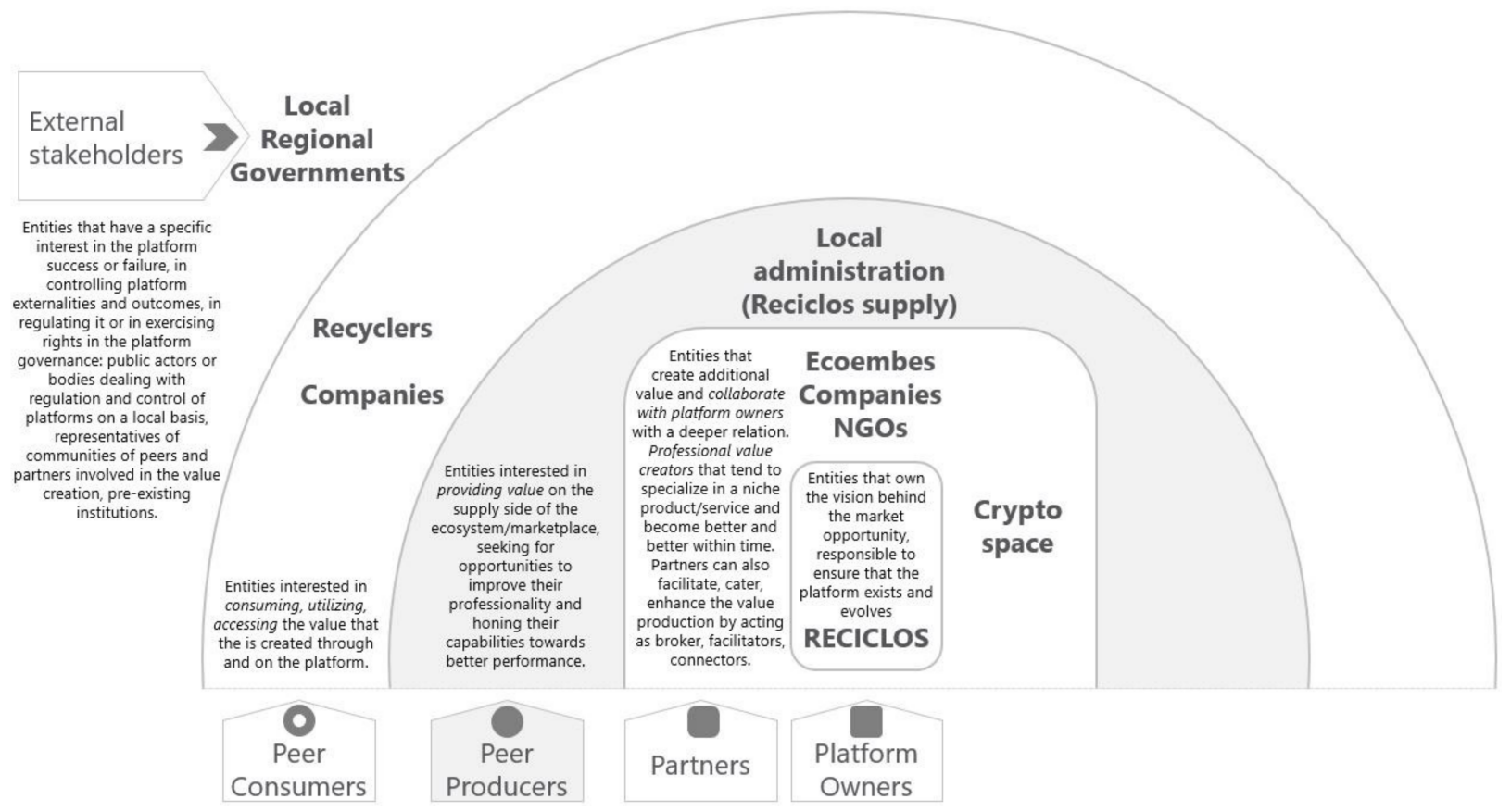

Figure 5. RECICLOS-main stakeholders. (Note: own elaboration based on [41]).

Vision-To integrate lotteries and virtual currencies to reward recycling results in a platform that would gradually cause a paradigm shift in terms of recycling and boost the recycling percentage to the expected percentages set by the legal framework, also enabling new business models powered by this strengthened community.

Mission-To empower recyclers by making them self-responsible, with no intermediary human actors for the most powerful recycling rewards program, since rewards are dealt with in an unmanned and decentralized manner. This is made possible today with Blockchain, realigning the actors to make them useful and more motivated to recycle.

\subsection{Limitations and Future Research}

Like any innovative solution, the initiative presented has some limitations. The RECICLOS pilot was implemented for 10 weeks in a relatively small area, meaning that it needs to be implemented in a larger territory with greater citizen and municipality participation to be validated. The incentives considered initially were mainly individual ones, and there was a limited range of incentives that benefit both the individual and society, such as donations to ONGs which, as the results show, should be used in a very limited way. Moreover, some limitations and difficulties emerged because of the quality of the plastic waste separation. While this issue remains key, imaginative solutions are needed to communicate to the end user the importance of this task being their responsibility. The system is not feasible if a third-party organization needs to check and/or correct waste selection and separation. Technology is ultimately useful and ready to be implemented in this area.

Future developments must focus on the design and piloting phases. New incentive schemes have been ideated with a high potential for success in terms of uptake and involve alternative improvements to the immediate neighbourhood such as new eco-friendly playgrounds and green mobility discounts or vouchers for shopping in local shops. To this effect, both the individual and the most immediate community are rewarded. Image 
recognition (for plastic bottles and metal cans), smart containers (for correct separation), and fraud avoidance and detection (to avoid erroneous rewards) are proof of how technology can enhance and perfect the system. Moreover, the creation of a functional business model, such as the one showed in Figure 6, and testing system validity in big cities with large cohort of users are key for future developments.

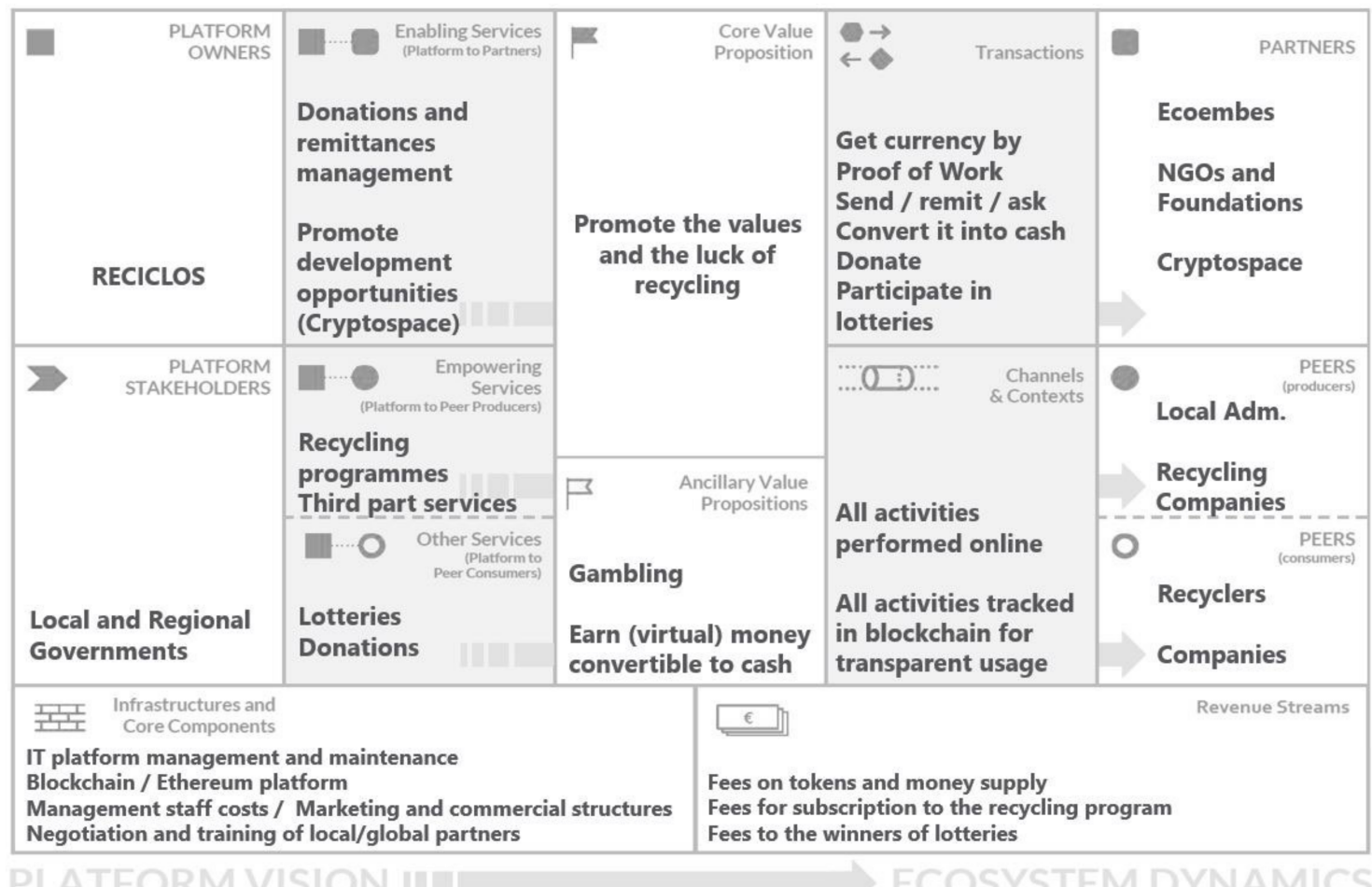

Figure 6. RECICLOS-Business model platform. (Note: own elaboration based on [41]).

A complementary, currently missing aspect in the present research is perception evaluation. Although the system proved feasible and accurate in terms of showing recycling behaviour performance and patterns that were extremely helpful for shaping new developments, user perception studies are also recommended. Future research should consider alternatives to the business model and stakeholder theory and possible theoretical frameworks such as the technology acceptance model and the diffusion of innovation theory, as well as service quality assessment in the field of recycling. There is also a need to investigate incentives together with other strategies to promote recycling because according to a recent study on recycling food waste in China 'social influences', with interpersonal interactions as an important element, dominate 'incentives' [16].

Against all these limitations and planned or on-going developments, RECICLOS was shown to make a valuable contribution and impact, producing a series of implications especially for policy. While recycling in general, and especially plastic recycling, has long been on the policy agenda, solutions have been slow to appear. Efforts must be ongoing to create environmental awareness to lower use and promote correct recycling to lower the impact.

\subsection{Sustainability of the Approach and Its Applicability in Other Contexts}

The population needs solutions that match the current way of operating in this area but are more efficient. Incentive schemes are needed initially until there is a change in attitude and behaviour. Public-private collaborative partnerships are required to ensure commitment and the diffusion of solutions. RECICLOS is an outstanding model of how a local public administration together with an innovative start-up can make the most of this alliance. Last, while the promotion of digitalization is already ongoing in almost all areas of 
life, it still needs to be more widespread in the area of recycling, generating advantages over traditional approaches. The digitalization of waste management and innovative solutions have high potential along the entire recycling value chain from separation and selection to rewards, also connecting and benefiting the tech-savvy communities of users. There are implications beyond the ones for policymakers, target end-users, businesses, and academia. End-users are guided and supported by a novel solution to their decision to recycle that has a direct impact on increased awareness of how to recycle correctly and recycling habits and their usefulness, while contributing to a community initiative and potentially leading to waste reductions and changes in habits. There are valuable recommendations for business, and especially the environmental consultancy and solutions field, and it is an illustration of how to deploy a successful project. Key success factors include "start small, dream big", but with a Minimum Viable Product (MPV) implemented in a small, carefully selected location that allows for testing and accepts the "learning by recycling" attitude. Next, implement actions that drive change, visualize and communicate success, and scale up a more mature and complex system, completing the innovation journey. Last, there are also considerable implications for local administrations. Promoting and embracing initiatives like this one not only provides them with support in pursuing environmental targets and avoiding penalties, but also contributes to their image and prestige, giving them a modern, renewed, environmentally and socially responsible image, and providing evidence that they are an important contributor to achieving a constructive, positive approach, and to changing behaviour.

\section{Conclusions}

"Plastics will continue to shape our present and our future, however, we will not be able to achieve the full potential of these extraordinary materials if we do not address the global challenges linked to their negative impact when they end up in the environment" [1]. This claim is a forceful call for imaginative solutions mainly rooted in and targeted at responsible consumption and recycling.

The multidimensional aspects of recycling activities, their strong relation with human behavioural patterns, and the high demand for communication and interactions open up a window of opportunity for mobile technologies to find significant application. Mobile phones are devices that can connect different stakeholders. Furthermore, people can be influenced and ultimately expected to change their recycling habits. More specifically, they can participate in social media discussions and be part of pro-environmental and recycling groups and campaigns that promote sustainable living and the recycling culture. People can also change their behaviour by playing games on mobile phones, the Internet, and tablets.

The benefit of the $20 \%$ discount is that the incentive effect was produced more by the gamification of the incentives through raffles and lotteries (over $70 \%$ ) than by the simple distribution of these discounts (less than 30\%), despite the surveys predicting a clear preference for the discount on the municipal waste tax. This finding is crucial because it means that there is opportunity not only for the municipal rubbish tax discount but also for other incentives in the short, medium, and long terms. Furthermore, gamification with raffles has been shown to have potential for further research. Notably, raffles are a gamified way to distribute discounts as opposed to dividing them pro rata, which as this research verifies dilutes the effect of the benefit expected in form at ratios of 1 to 10, 100, or even 1000. These ratios maintain the possibility that users will be motivated to choose this option above other types of lotteries where the prize plays a much larger role, but participants are aware that the chances of them winning it is much lower. The conclusion is that people prefer raffles 8 times more than lotteries and 2 times more than discounts.

Innovative solutions, such as the one described in the present research, which are compatible with current habits while generating a relative advantage and producing observable results (incentive), are valuable and worth raising the profile of while contributing to environmental awareness, more and better recycling habits, and potential long-term 
change for the future. This future can only be achieved by sustainable development (SD), a "development that meets the needs of the present without compromising the ability of future generations to meet their own needs". It is nowadays not a question of "if" but rather "how" SD principles can and should be applied and spread. In this line, RECICLOS is directly aligned with at least three of the SD goals set by the United Nations, namely, (i) 11: Sustainable cities and communities-Make cities and human settlements inclusive, safe, resilient, and sustainable, (ii) 12: Responsible consumption and production: Ensure sustainable consumption and production patterns, and (iii) 17: Partnership for the goals-Strengthen the means of implementation and revitalize the global partnership for sustainable development. Beyond these, indirect relations are also present with goals 9-Industry, innovation, and infrastructure, 13-Climate action, 14-Life below water, 15-Life on land. This alignment shows the magnitude and cross-cutting nature of recycling, an area where much has been done but there remains a long way to go.

Author Contributions: Conceptualization, D.G.; methodology, D.G. and A.B.; validation, D.G.; formal analysis, D.G.; writing — original draft preparation, D.G.; writing—review and editing, D.G. and A.B.; supervision, A.B.; project administration, D.G.; funding acquisition, D.G. and A.B. All authors have read and agreed to the published version of the manuscript.

Funding: This research received no external funding. The APC was funded by the Department of Business Administration and Product Design (University of Girona).

Data Availability Statement: Restrictions apply to the availability of these data. Data was obtained from Ecoembes and are available from the corresponding author with the permission of Ecoembes.

Conflicts of Interest: The authors declare no conflict of interest.

\section{References}

1. PlasticsEurope. Plastics - the Facts 2020; PlasticsEurope: Brussels, Belgium, 2020.

2. Ellen MacArthur Foundation. The New Plastics Economy: Rethinking the Future of Plastics; Ellen Macarthur Foundation: Cowes, UK, 2016; p. 120.

3. Pan-European Partnership of Specialist Organisations (EPRO). Plastics—the Facts 2018; EPRO: Brussels, Belgium, 2018.

4. European Commission. A European Strategy for Plastics in a Circular Economy; European Commission: Brussels, Belgium, 2018.

5. EUROSTAT Packaging Waste Statistics. Available online: https://ec.europa.eu/eurostat/statistics-explained/index.php/ Packaging_waste_statistics (accessed on 24 January 2021).

6. Jambeck, J.; Geyer, R.; Wilcox, C.; Siegler, T.R.; Perryman, M.; Andrady, A.; Narayan, R.; Law, K.L. Plastic waste inputs from land into the ocean. Mar. Pollut. 2015, 347, 768-771. [CrossRef] [PubMed]

7. Lavers, J.L.; Bond, A.L. Exceptional and rapid accumulation of anthropogenic debris on one of the world's most remote and pristine islands. Proc. Natl. Acad. Sci. USA 2017, 114, 6052-6055. [CrossRef] [PubMed]

8. João, P.D.C.; Teresa, R.-S.; Armando, C.D. The Environmental Impacts of Plastics and Micro-Plastics Use, Waste and Pollution: EU and National Measures; European Union: Brussels, Belgium, 2020.

9. PlasticsEurope. PlasticsEurope Market Research Group (PEMRG)/Consultic Marketing E Industrieberatung GmbH Plastics-The Facts 2017; PlasticsEurope: Bruxelles, Belgium, 2017; p. 16. [CrossRef]

10. Rada, E.C.; Ionescu, G.; Ferronato, N.; Ragazzi, M.; Raspanti, M.; Conti, F.; Torretta, V. Zooming on light packaging waste differences by scanning electron microscopy. Environ. Sci. Pollut. Res. 2020, 1-7. [CrossRef] [PubMed]

11. Bilitewski, H.C.B. Pay-as-you-throw-A tool for urban waste management. Waste Manag. 2008, 28, 2759. [CrossRef]

12. Rada, E.C.; Zatelli, C.; Cioca, L.I.; Torretta, V. Selective collection quality index for municipal solid waste management. Sustainability 2018, 10, 257. [CrossRef]

13. European Commission. Commission Staff Working Document Accompanying the Document Communication from the Commission to the European Parliament, the Council, the European Economic and Social Committee and the Committee of the Regions A European Strategy for Plastics in a Circul; European Commission: Brussels, Belgium, 2018.

14. Rada, E.C.; Zatelli, C.; Mattolin, P. Municipal solid waste selective collection and tourism. WIT Trans. Ecol. Environ. 2014, 180, 187-197. [CrossRef]

15. Castagna, A.; Casagranda, M.; Zeni, A.; Girelli, E.; Rada, E.C.; Ragazzi, M.; Apostol, T. 3R'S from citizens point of view and their proposal from a case-study. UPB Sci. Bull. Ser. D Mech. Eng. 2013, 75, 253-264.

16. Li, C.; Wang, Y.; Li, Y.; Huang, Y.; Harder, M.K. The incentives may not be the incentive: A field experiment in recycling of residential food waste. Resour. Conserv. Recycl. 2020, 168, 105316. [CrossRef]

17. Government of Spain. Circular Spain 2030; Government of Spain: Madrid, Spain, 2018. 
18. Ecoembes Citizens. Available online: https://www.ecoembes.com/es/ciudadanos/envases-y-proceso-reciclaje/datos-dereciclaje-en-espana (accessed on 25 January 2021).

19. Kirchherr, J.; Reike, D.; Hekkert, M. Conceptualizing the circular economy: An analysis of 114 definitions. Resour. Conserv. Recycl. 2017, 127, 221-232. [CrossRef]

20. Reike, D.; Vermeulen, W.J.V.; Witjes, S. The circular economy: New or Refurbished as CE 3.0?-Exploring Controversies in the Conceptualization of the Circular Economy through a Focus on History and Resource Value Retention Options. Resour. Conserv. Recycl. 2018, 135, 246-264. [CrossRef]

21. EU Plastic Waste: Ecological and Human Health Impacts. In Science for Environment Policy in-Depth Report; DG Environment News Alert Service. European Commission Directorate General; European Commission: Brussels, Belgium, 2011.

22. Timlett, R.E.; Williams, I.D. Public participation and recycling performance in England: A comparison of tools for behaviour change. Resour. Conserv. Recycl. 2008, 52, 622-634. [CrossRef]

23. Abila, B.; Kantola, J. The Perceived Role of Financial Incentives in Promoting Waste Recycling—Empirical Evidence from Finland. Recycling 2019, 4, 4. [CrossRef]

24. Abila, B. Households' perception of financial incentives in endorsing sustainable waste recycling in Nigeria. Recycling 2018, 3, 28. [CrossRef]

25. Bartolotta, J.F.; Hardy, S.D. Barriers and benefits to desired behaviors for single use plastic items in northeast Ohio's Lake Erie basin. Mar. Pollut. Bull. 2018, 127, 576-585. [CrossRef] [PubMed]

26. Puig-Ventosa, I. Charging systems and PAYT experiences for waste management in Spain. Waste Manag. 2008, 28, 2767-2771. [CrossRef]

27. Šauer, P.; Pařízková, L.; Hadrabová, A. Charging systems for municipal solid waste: Experience from the Czech Republic. Waste Manag. 2008, 28, 2772-2777. [CrossRef] [PubMed]

28. Skumatz, L.A. Pay as you throw in the US: Implementation, impacts, and experience. Waste Manag. 2008, 28, 2778-2785. [CrossRef]

29. Le Bozec, A. The implementation of PAYT system under the condition of financial balance in France. Waste Manag. 2008, 28, 2786-2792. [CrossRef]

30. Karagiannidis, A.; Xirogiannopoulou, A.; Tchobanoglous, G. Full cost accounting as a tool for the financial assessment of Pay-As-You-Throw schemes: A case study for the Panorama municipality, Greece. Waste Manag. 2008, 28, 2801-2808. [CrossRef]

31. Sakai, S.; Ikematsu, T.; Hirai, Y.; Yoshida, H. Unit-charging programs for municipal solid waste in Japan. Waste Manag. 2008, 28, 2815-2825. [CrossRef]

32. Dunne, L.; Convery, F.J.; Gallagher, L. An investigation into waste charges in Ireland, with emphasis on public acceptability. Waste Manag. 2008, 28, 2826-2834. [CrossRef]

33. Olander, S.; Landin, A. Evaluation of stakeholder influence in the implementation of construction projects. Int. J. Proj. Manag. 2005, 23, 321-328. [CrossRef]

34. Mak, T.M.W.; Yu, I.K.M.; Wang, L.; Hsu, S.C.; Tsang, D.C.W.; Li, C.N.; Yeung, T.L.Y.; Zhang, R.; Poon, C.S. Extended theory of planned behaviour for promoting construction waste recycling in Hong Kong. Waste Manag. 2019, 83, 161-170. [CrossRef]

35. Mavropoulos, A.; Anthouli, A.; Tsakona, M. Mobile Applications and Waste Management: Recycling, Personal Behavior, Logistics; D-Waste Environmental Consultants Ltd.: Athens, Greece, 2013.

36. Isa, M.H.; Asaari, F.A.H.; Ramli, N.A.; Ahmad, S.; Siew, T.S. Solid waste collection and recycling in Nibong Tebal, Penang, Malaysia: A case study. Waste Manag. Res. 2005, 23, 565-570. [CrossRef]

37. Diaz-Barriga-Fernandez, A.D.; Santibañez-Aguilar, J.E.; Radwan, N.; Nápoles-Rivera, F.; El-Halwagi, M.M.; Ponce-Ortega, J.M. Strategic Planning for Managing Municipal Solid Wastes with Consideration of Multiple Stakeholders. ACS Sustain. Chem. Eng. 2017, 5, 10744-10762. [CrossRef]

38. De la Rosa, J.L. Rewarding Recycling Plastic Proof of Concept with Tokenization and Smartcontracts in Alastria. In Alastria Mission and Vision-A Multidisciplinary Research; Editorial Reus SA: Reus, Spain, 2020.

39. Biddle, D. Recycling for Profit: The New Green Business Frontier. Available online: https://hbr.org/1993/11/recycling-forprofit-the-new-green-business-frontier (accessed on 31 January 2021).

40. Chesbrough, H.; Rosenbloom, R.S. The role of the business model in capturing value from innovation: Evidence from Xerox Corporation's technology spin-off companies. Ind. Corp. Chang. 2002, 11, 529-555. [CrossRef]

41. Platform Design Toolkit. Available online: https://platformdesigntoolkit.com/toolkit/ (accessed on 28 February 2021). 